\title{
Hydrocarbon-based fuel cell membranes: Sulfonated crosslinked poly(1,3-cyclohexadiene) membranes for high temperature polymer electrolyte fuel cells
}

Suxiang Deng ${ }^{\text {a }}$, Mohammad K. Hassan ${ }^{\text {b }}$, Kenneth A. Mauritz ${ }^{\text {c }}$, Jimmy W. Mays ${ }^{\text {a,* }}$

a Department of Chemistry, University of Tennessee, 1420 Circle Drive, Knoxville, TN 37996, USA

${ }^{\mathrm{b}}$ Center for Advanced Materials, Qatar University, Doha, Qatar

${ }^{\mathrm{c}}$ School of Polymers and High Performance Materials, The University of Southern Mississippi, 118 College Drive, Hattiesburg, MS 39406, USA

${ }^{*}$ Corresponding author.

E-mail address: jimmymays@utk.edu (J.W. Mays)

Keywords:

Fuel cell membranes

Proton conductivity

Sulfonation

ABSTRACT 
High temperature fuel cell membranes based on poly(1,3-cyclohexadiene) were prepared by a Polymerization-Crosslinking-Sulfonation (PCS) approach, and a broad range of membrane compositions were achieved using various sulfonating reagents and reaction conditions. Membranes were characterized for their proton conductivity and thermal degradation behavior. Some of the membranes showed up to a $68 \%$ increase in proton conductivity as compared to Nafion under the same conditions $\left(100 \%\right.$ relative humidity and $\left.120{ }^{\circ} \mathrm{C}\right)$. Thermogravimetric analysis revealed that these membranes are thermally stable up to $200{ }^{\circ} \mathrm{C}$. High proton conductivity and thermal stability, combined with much lower cost as compared to $\mathrm{Nafion}^{\circledR}$, make these materials potentially interesting as fuel cell membranes, although they are chemically vulnerable under fuel cell operation conditions.

\section{Introduction}

Fuel cells have attracted considerable interest as one of the most promising clean energy generators because of their high efficiency and benign byproduct that consists simply of water [1]. Proton exchange membrane fuel cells (PEMFCs) are operated typically at moderate temperatures $\left(60-80{ }^{\circ} \mathrm{C}\right)$ and efficiently generate high power densities making them attractive for use in automotive vehicles. The key component in a PEMFC is the proton exchange membrane which ideally would have high proton conductivity, good mechanical properties in both dry and hydrated states, oxidative and hydrolytic stability, low cost, and the ability to be incorporated into membrane electrode assemblies (MEAs). Some PEMs are of the perfluorosulfonic acid (PFSAs) variety, such as Nafion ${ }^{\circledR}$ (E.I. DuPont), which possess high proton conductivity and chemical stability as compared to some hydrocarbon-based membranes $[2,3,4,5]$. However, high cost and difficult synthesis has limited their applications. Two additional drawbacks of PFSAs are low proton conductivity at low RH and poor mechanical stability at elevated temperatures $\left(\mathrm{T}>80^{\circ} \mathrm{C}\right)[6,7,8,9]$. PFSA conductivity decreases as $\mathrm{RH}$ decreases because there is a loss of contiguous water molecules along which protons are transported [10]. Conductivity increases slightly as temperature increases [11] but then decreases dramatically above $90{ }^{\circ} \mathrm{C}$ due to membrane dehydration. Moreover, PFSAs have low glass transition temperatures $\left(T_{\mathrm{g}}\right)$ so that they lose material integrity at higher temperatures $\left(\mathrm{T}>100{ }^{\circ} \mathrm{C}\right)$ which leads to mechanical failure, pinhole formation, thinning and the damaging effects of swelling hysteresis. Due to these two drawbacks, current PEMFCs require thermal and water management to maintain operating temperature and membrane humidification, all of which increases system complexity. On the other hand, operating fuel cells at higher temperatures (up to $120^{\circ} \mathrm{C}$ ) and at lower $\mathrm{RH}$ is attractive for a number of reasons. These include (a) reduced system complexity by limiting or eliminating excess water supply to the fuel cell; (b) simplification of the cooling system; (c) improved tolerance of electrodes to carbon monoxide; (d) 
possible use of co-generated heat; (e) increased proton conductivity; (f) less required catalysts due to increased catalytic activity at higher temperature.

Considerable effort has been devoted to high temperature-operating membranes, in particular those composed of non-perfluorinated materials because of material cost, better environmental properties when discarded and lower production costs $[12,13]$. For automotive applications the U.S. Department of Energy set a target conductivity of $0.1 \mathrm{~S} / \mathrm{cm}$ at $120{ }^{\circ} \mathrm{C}$ and $50 \%$ relative humidity (RH).

Hydrocarbon membranes can be economical alternatives to perfluorinated membranes on the condition that they withstand attack by peroxy and hydroperoxy radicals generated in situ. The factors that control chemical and mechanical durability are coupled and a study of this relationship would constitute a considerable effort in itself. While it would be ideal, in a single effort, to optimize water structure and distribution for optimal proton conductivity, as well as good chemical and mechanical durability, it is realistic to focus on and understand the results of manipulating a limited number of experimental variables. In the work reported herein, chemical and physical durability issues are not addressed and the emphasis is on exploring chemical structure and its effect on proton conductivity.

Poly(1,3-cyclohexadiene) (PCHD) is of interest for use in alternative high temperature fuel cell membranes because of its unique structure, potentially low cost, and ease of post-polymerization modification. As we reported previously [14], PCHD with the desired microstructure (1,4- vs. 1,2-) and molecular weight can be synthesized via anionic polymerization. The in-chain six-member ring structure of PCHD imparts a semi-flexible character to PCHD, with higher glass transition temperatures $\left(>100^{\circ} \mathrm{C}\right)$ and better thermal stability as compared with typical polydienes $[15,16,17,18]$. The double bonds in the ring structure of PCHD can be chemically modified through a host of reactions including hydrogenation [19], aromatization [20], sulfonation [21] and even fluorination [22]. These chemical modifications allow for tuning key performance properties such as proton transport, hydrophilicity, gas permeability, mechanical properties, morphology, thermal stability, crystallinity, and cost. Therefore, PCHD-based membranes may be considered as model systems that have a number of variables which can be manipulated to optimize properties for fuel cells, as well as other potential applications such as dehumidification and desalination.

In this paper, we report our PCS (Polymerization-Crosslinking-Sulfonation) approach to create high temperature fuel cell membranes based on PCHD (see Scheme 1). 1,3-Cyclohexadiene was polymerized using the sec-BuLi/1,4-diazabicyclo[2,2,2]octane (DABCO) complex to yield linear PCHDs, which were then crosslinked with sulfur monochloride to give smooth thin membranes. It will be seen that sulfonation endows the resulting fuel cell membranes with high proton conductivity and good mechanical properties. These materials were characterized using proton nuclear magnetic resonance 
spectroscopy ( ${ }^{1} \mathrm{H}$ NMR), gel permeation chromatography (GPC), elemental analysis, thermogravimetric analysis (TGA), water uptake, and proton conductivity measurements.

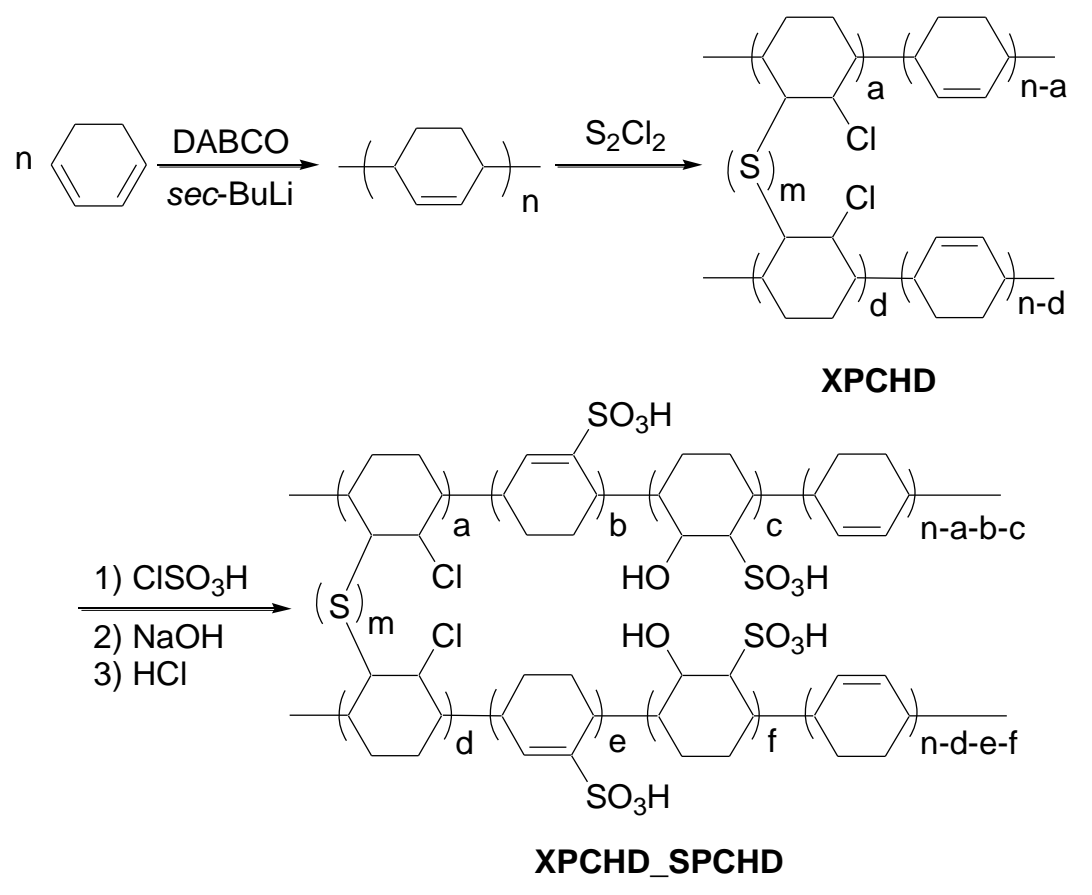

Scheme 1. PCS approach to poly(1,3-cyclohexadiene)-based fuel cell membranes.

\section{Experimental section}

\subsection{Materials}

Benzene (Fisher, 99\%), 1,3-cyclohexadiene (Aldrich, 98\%), and 1,4-diazabicyclo- [2.2.2]octane (DABCO, Aldrich, 98\%) were purified, and linear PCHD was synthesized as previously reported [14]. sec-Butyllithium (Aldrich, 1.4 M in cyclohexane), carbon disulfide (99.9\%, Aldrich), sulfur monochloride (99.9\%, Aldrich), chlorosulfonic acid (98\%, Fluka), 1,2-dichloroethane (99.8\%, Aldrich), 2,6-di-tert-butyl-4-methylphenol (BHT, Aldrich, 99\%), and all other solvents were used as received.

\subsection{Membrane casting: Formation of membranes XPCHD}

All membrane casting was performed under ambient conditions without $\mathrm{N}_{2}$ protection. The molar ratio of $\mathrm{S}_{2} \mathrm{Cl}_{2}$ to double bonds in PCHD was varied from $10 \%$ to $25 \%$ unless otherwise stated. In a typical membrane casting experiment, $0.30 \mathrm{~g}$ of $\mathrm{S}_{2} \mathrm{Cl}_{2}(2.2 \mathrm{mmol})$ in toluene $(3.0 \mathrm{~mL})$ was added dropwise into a solution of linear PCHD (1.50 g, $18.7 \mathrm{mmol}$ double bond units) in toluene (25.0 mL). After addition, the reaction mixture was stirred at room temperature for about 1 hour, divided evenly 
into three portions, and then poured into three Fisher brand Low-Form PTFE dishes (Diameter: 100mm; Capacity: 100mL). The solvent was allowed to evaporate slowly overnight in the hood. After immersion in $\mathrm{CS}_{2}$ hexane solution $(5 \mathrm{v} \%, 20 \mathrm{~mL})$ for about $30 \mathrm{~min}$., the membranes were peeled off carefully with a spatula, washed with hexane twice, and dried under vacuum overnight while being pressed between desiccator plates. Thickness of a typical membrane was about $120 \mu \mathrm{m}$.

\subsection{Sulfonation of crosslinked PCHD membranes: preparation of fuel cell membranes XPCHD-}

\section{SPCHD}

All sulfonation experiments were performed under $\mathrm{N}_{2}$ protection to reduce the interference of moisture. Various sulfonating reagents including acetyl sulfonate, $\mathrm{SO}_{3} /$ dioxane, $\mathrm{ClSO}_{3} \mathrm{H} /$ dioxane, $\mathrm{ClSO}_{3} \mathrm{H} /$ diethyl ether, and $\mathrm{ClSO}_{3} \mathrm{H}$ were used. The molar ratio of sulfonating reagent to double bonds in XPCHD (calculated as before crosslinking) was from 1.4 to 7 unless otherwise stated. In a typical sulfonation experiment, about $350 \mathrm{~mL}$ of anhydrous 1,2-dichloroethane was added onto a crosslinked

membrane XPCHD ( $0.50 \mathrm{~g}, 6.2 \mathrm{mmol}$ double bond units) placed above a fritted disc (Diameter: 125 $\mathrm{mm}$; coarse) in a $2000 \mathrm{~mL}$ cylindrical reactor. A solution of $\mathrm{ClSO}_{3} \mathrm{H}(4.00 \mathrm{~g}, 34.33 \mathrm{mmol}, 5.50$ molar equivalent) in 1,2-dichloroethane $(\sim 10 \mathrm{~mL})$ was added dropwise and the reaction mixture was heated to refluxing for about $3 \mathrm{hrs}$. After cooling to room temperature, the membrane was removed, washed with methylene chloride, and immersed in $\mathrm{NaOH}$ solution $(\sim 10 \mathrm{wt} \%, 50 \mathrm{~mL})$ for $1 \mathrm{~h}$. The membrane was washed with deionized water and converted into the acidic form by immersing in dilute $\mathrm{HCl}$ solution $(\sim$ $5 \%$ ) at r.t. for $30 \mathrm{~min}$. The membrane was then rinsed thoroughly with deionized water to remove any residual acid and dried under vacuum overnight while being pressed between two desiccator plates.

To quantify degree of crosslinking and sulfonation, fuel cell membrane samples were sent to Galbraith Laboratories, Inc. (Knoxville, TN) for elemental analysis. CHNS analysis was done with combustion method. Analysis of oxygen was conducted using an oxygen analyzer. Analysis for chlorine was carried out with a Total Organic Halogen (TOX) Analyzer.

\subsection{Membrane in-plane proton conductivity}

Initial membrane proton conductivity $(\sigma)$ measurements were limited to samples being in liquid water at room temperature for rapid screening. Samples were mounted in a four point probe conductivity cell. Before electrical impedance $\left(Z^{*}=Z^{\prime}-i Z^{\prime \prime}, i=\sqrt{ }-1\right)$ data was acquired over the frequency range $1 \mathrm{KHz}-1 \mathrm{MHz}$ the samples were soaked in water for $24 \mathrm{~h}$. The $Z^{\prime}$ intercept of $Z^{\prime \prime}$ vs. $Z^{\prime}$ plots was taken, in usual fashion, as the membrane resistance that was used to compute conductivity. 
The conductivity of selected membranes was further investigated as function of relative humidity (RH) at 30, 80, and $120^{\circ} \mathrm{C}$ at Bekktech, LLC (now Scribner Associates Inc.) facilities. Membrane inplane proton conductivity vs. RH at each temperature was determined using a BekkTech (BT-512) fourpoint probe conductivity test system. Sample dimensions were $4.2 \mathrm{~mm}$ in length and of $5.4 \mathrm{~mm}$ in width. Samples were clamped in place and equilibrated in steps of RH holding RH constant for 15 min. A back pressure of $230 \mathrm{kPa}$ absolute was used during the $120{ }^{\circ} \mathrm{C}$ measurement to prevent water desorption.

\subsection{Thermogravimetric analysis (TGA)}

Thermogravimetric analysis was performed using a TA Q50 instrument Thermogravimetric Analyzer with $\mathrm{N}_{2}$ as purging gas. Tests were conducted from 25 to $800{ }^{\circ} \mathrm{C}$ at a heating rate of 10 ${ }^{\circ} \mathrm{C} / \mathrm{min}$.

\subsection{Water uptake}

Equilibrium water uptakes of the membranes at $80{ }^{\circ} \mathrm{C}$ over a range of $\mathrm{RH}$ were measured by subjecting the hydrated samples to an isothermal desorption using a TA Q5000SA Moisture Analyzer. The samples were examined over the range of $10-90 \%$ RH by decreasing the humidity by $10 \%$ per hour. The water uptake was calculated by the following equation:

$$
\text { Water uptake }=\left[\left(\mathrm{W}_{\text {wet }}-\mathrm{W}_{\mathrm{dry}}\right) / \mathrm{W}_{\mathrm{dry}}\right] \times 100 \%
$$

$\mathrm{W}_{\text {wet }}$ is the weight of the sample at a particular humidity and $\mathrm{W}_{\text {dry }}$ is the weight of the sample at $0 \% \mathrm{RH}$.

\section{Results and discussion}

\subsection{Polymerization of 1,3-cyclohexadiene: Synthesis of PCHD}

1,3-Cyclohexadiene can undergo both 1,2- and 1,4-polymerization. With DABCO as the additive and sec-BuLi as the initiator, 1,4-polymerization is the dominant reaction and linear PCHDs with 1,4microstructure content greater than 90\% were obtained [14]. High 1,4-microstructure content imparts PCHD with semi-rigidity and higher glass transition temperatures $\left(\mathrm{T}_{\mathrm{g}}>100^{\circ} \mathrm{C}\right)$ as compared with typical polydienes [15-18]. Moreover, high 1,4-PCHDs have much higher solubility (about double) in common organic solvents such as toluene as compared to PCHDs with higher 1,2-microstructure (ca. $50 \%$ ) at the same molecular weights. Therefore, high 1,4-PCHD is inherently more suitable than high 
1,2-PCHD for applications in high temperature fuel cell membranes. The ratios of 1,4- to 1,2microstructure in PCHDs were estimated from the relative areas of protons adjacent to the double bond ( $\alpha$ positions) and those in the $\beta$ positions [14]. Reaction conditions of $s e c-\mathrm{BuLi} / \mathrm{DABCO} / 20{ }^{\circ} \mathrm{C}$ in benzenes [14] were carefully controlled so that all synthesized PCHDs have 1,4-microstructure content higher than $90 \%(91 \% \sim 96 \%)$.

Very narrow molecular weight distributions are not necessary in this work because the next step in membrane formation is crosslinking. Thus, commercially available sec-BuLi was used instead of freshly synthesized initiator and polymerizations were conducted under inert atmosphere conditions instead of under high vacuum conditions as in our prior work [14]. The use of a commercially available initiator under inert atmosphere offers higher mass production potential than synthesis under high vacuum conditions often employed in our lab for anionic polymerization.

Molecular weights higher than 5,000 are necessary for PCHDs to ensure polymer chain entanglements/crosslinking that are responsible for producing physically robust films for use as PEMs. Conversely, PCHDs with molecular weights higher than 30,000 have quite poor solubility in common organic solvents such as toluene, chloroform, and THF, making crosslinking practically difficult. Thus PCHDs with molecular weight ranging from 5,000 to 25,000 and polydispersities ranging from 1.25 to 1.85 were synthesized for membrane casting.

\subsection{Crosslinking of PCHD: formation of XPCHD membrane}

Attempts to cast PCHD membranes without crosslinking failed. PCHD has a unique structure comprised of six-membered rings in its backbone. The connecting ring structure leads to a relatively rigid polymer backbone, making uncrosslinked PCHD too fragile to form intact membranes. On the other hand, sulfonated PCHDs with more than $30 \%$ sulfonation have very limited solubility in common organic solvents, making crosslinking of sulfonated PCHDs practically difficult. Therefore, crosslinking of PCHD before sulfonation is an essential step to form flexible smooth thin membranes.

The integrity of fuel cell membranes is enhanced by crosslinking. Without crosslinking, microscopic crazes/cracks/pinholes can form and spread when the polymer is sulfonated. These defects can be caused and exacerbated with swelling-deswelling during relative humidity (RH) cycling in a fuel cell. Crosslinking effectively "locks in" the morphology; i.e. membrane morphology does not depend on casting solvent and casting conditions. Other membrane properties such as flexibility, homogeneity, and mechanical strength are also important. All these properties could be affected by (1) molecular weight of PCHD, (2) film casting solvent, (3) PCHD concentration in solutions to be cast, (4) molar ratio of crosslinking reagent $\mathrm{S}_{2} \mathrm{Cl}_{2}$ to double bond units in PCHD, (5) mixing conditions prior to film formation and (6) rate of solvent evaporation. Among these factors, molecular weight, concentration of PCHD, 
and molar ratio of $\mathrm{S}_{2} \mathrm{Cl}_{2}$ are most important. In general, when PCHD of higher molecular weight was used, lower polymer concentrations should be used in order to avoid gelation before casting. With PCHD of 10,000 in molecular weight, a typical concentration of $5 \mathrm{wt} \%$ was used, while for PCHD of 20,000, only $3 \mathrm{wt} \%$ concentration could be used. Besides molecular weight and concentration of PCHD, the molar ratio of $\mathrm{S}_{2} \mathrm{Cl}_{2}$ to double bond units in PCHD is probably the most important factor. With a molar ratio of $\mathrm{S}_{2} \mathrm{Cl}_{2}$ lower than $10 \%$, the resulting membranes tend to break into pieces when being peeled off a PTFE dish because of insufficient crosslinking. On the other hand, with $\mathrm{S}_{2} \mathrm{Cl}_{2}$ molar ratio higher than $25 \%$ the internal stresses caused by too much crosslinking appear to be responsible for cracking. Therefore, it is necessary to keep the $\mathrm{S}_{2} \mathrm{Cl}_{2}$ molar ratio between 10 and $25 \%$ and it seems that a $\sim 12 \%$ molar ratio gives the best quality films. Membrane thicknesses were controlled by the amount of PCHD and the diameter of the membrane casting dish. For a membrane of $100 \mathrm{~mm}$ in diameter and cast from $0.5 \mathrm{~g}$ of PCHD, the thickness is about $120 \mu \mathrm{m}$ (see Fig. 1). Thinner membranes could be easily made by using less PCHD and/or larger dishes.

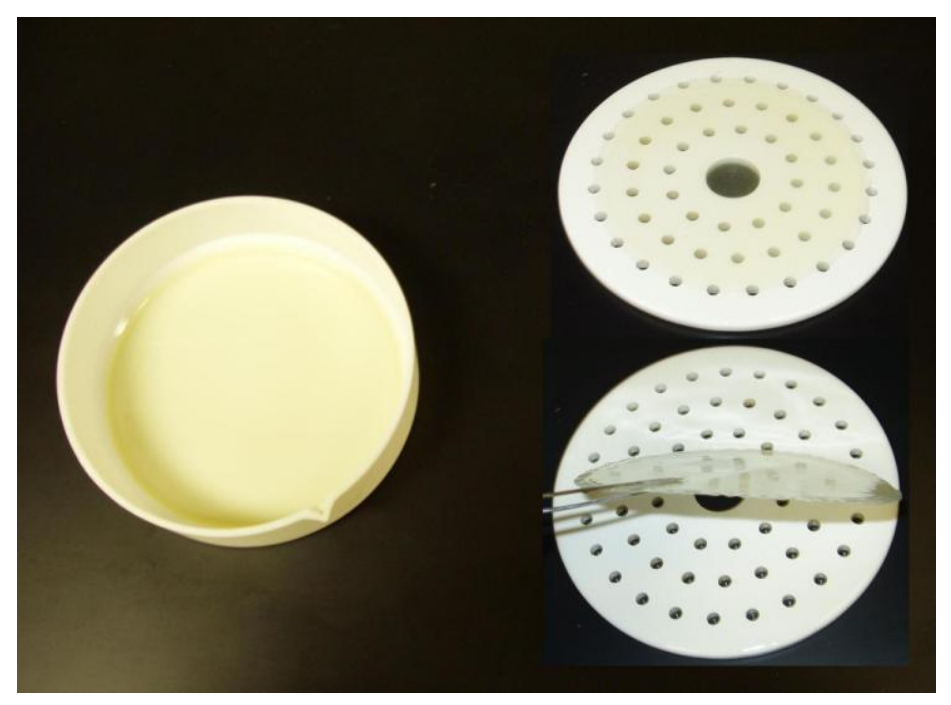

Fig. 1. Crosslinked XPCHD membrane.

Attempts to monitor the crosslinking process by using FT-IR spectroscopy failed because the concentration of cross-linked units in the network was too low for IR detection. The membranes after crosslinking were also subjected to elemental analysis. The results gave the extent of crosslinking as $3 \%$ $\sim 12 \mathrm{~mol} \%$. With the $12 \%$ molar ratio of $\mathrm{S}_{2} \mathrm{Cl}_{2}$, the degree of crosslinking was estimated to be about $3 \%$ (see Table 1, XPCHD_10) based on chlorine content, assuming every $\mathrm{S}_{2} \mathrm{Cl}_{2}$ reacts with two double bonds from two different polymer chains and side-reactions such as hydrochlorination are negligible. 
Therefore, the efficiency of crosslinking is about 13\%. This low efficiency is attributed to the decomposition of $\mathrm{S}_{2} \mathrm{Cl}_{2}$ on storage and during membrane casting due to moisture in the air. The ratio of sulfur atoms to chlorine atoms in the crosslinked membranes varied from 1.0 to 3.3 (see Table 1). Therefore, the average bridge length ( $\mathrm{m}$ in Scheme 1) varies from 2 to 6 sulfur atoms. Even with the same concentration of PCHD solution and molar ratio of $\mathrm{S}_{2} \mathrm{Cl}_{2}$, both the degree of crosslinking and the ratio of $\mathrm{S} / \mathrm{Cl}$ still varied (see Table 1, XPCHD_2, 3, 4, 5, 7, and 8), indicating the crosslinking is actually a very complicated process. It should be noted that the use of sulfur monochloride as crosslinking agent would probably be a poor choice for a practical membrane but was used in this work because it allows crosslinking to be easily characterized. Other crosslinking agents such as peroxides could readily be employed.

\section{Table 1}

Crosslinking conditions and degree of crosslinking as determined from elemental analysis.

\begin{tabular}{ccclcc}
\hline Sample Names & $\begin{array}{c}\text { Concentration } \\
(\text { wt } \%)\end{array}$ & $\begin{array}{c}\mathrm{S}_{2} \mathrm{Cl}_{2} \text { ratio } \\
(\text { molar \%) }\end{array}$ & \multicolumn{1}{c}{ Calculated formula ${ }^{l}$} & $\begin{array}{c}\text { Crosslinking } \\
\text { (molar } \%)\end{array}$ & $\begin{array}{c}\text { Ratio of } \\
\mathrm{S} / \mathrm{Cl}\end{array}$ \\
\hline XPCHD_1 & 2.0 & 19 & $\mathrm{C}_{6.00} \mathrm{H}_{5.46} \mathrm{~S}_{0.22} \mathrm{Cl}_{0.12}$ & 12 & 1.8 \\
XPCHD_2 & 2.0 & 12 & $\mathrm{C}_{6.00} \mathrm{H}_{8.39} \mathrm{~N}_{0.03} \mathrm{~S}_{0.11} \mathrm{Cl}_{0.11} \mathrm{O}_{0.14}$ & 11 & 1.0 \\
XPCHD_3 & 2.0 & 12 & $\mathrm{C}_{6.00} \mathrm{H}_{8.48} \mathrm{~N}_{0.03} \mathrm{~S}_{0.06} \mathrm{Cl}_{0.03} \mathrm{O}_{0.05}$ & 3 & 2.0 \\
XPCHD_4 & 2.0 & 12 & $\mathrm{C}_{6.00} \mathrm{H}_{8.43} \mathrm{~N}_{0.03} \mathrm{~S}_{0.11} \mathrm{Cl}_{0.05} \mathrm{O}_{0.09}$ & 5 & 2.2 \\
XPCHD_5 & 2.0 & 12 & $\mathrm{C}_{6.00} \mathrm{H}_{8.32} \mathrm{~N}_{0.03} \mathrm{~S}_{0.11} \mathrm{Cl}_{0.08} \mathrm{O}_{0.09}$ & 8 & 1.4 \\
XPCHD_6 & 2.0 & 12 & $\mathrm{C}_{6.00} \mathrm{H}_{8.30} \mathrm{~N}_{0.03} \mathrm{~S}_{0.14} \mathrm{Cl}_{0.06} \mathrm{O}_{0.09}$ & 6 & 2.3 \\
XPCHD_7 & 2.0 & 12 & $\mathrm{C}_{6.00} \mathrm{H}_{8.00} \mathrm{~N}_{0.03} \mathrm{~S}_{0.10} \mathrm{Cl}_{0.05} \mathrm{O}_{0.06}$ & 5 & 2.0 \\
XPCHD_8 & 2.0 & 12 & $\mathrm{C}_{6.00} \mathrm{H}_{7.85} \mathrm{~N}_{0.03} \mathrm{~S}_{0.12} \mathrm{Cl}_{0.07} \mathrm{O}_{0.08}$ & 7 & 1.7 \\
XPCHD_9 & 3.0 & 12 & $\mathrm{C}_{6.00} \mathrm{H}_{8.26} \mathrm{~N}_{0.03} \mathrm{~S}_{0.17} \mathrm{Cl}_{0.07} \mathrm{O}_{0.09}$ & 7 & 2.4 \\
XPCHD_10 & 5.0 & 12 & $\mathrm{C}_{6.00} \mathrm{H}_{8.10} \mathrm{~S}_{0.10} \mathrm{Cl}_{0.03}$ & 3 & 3.3 \\
XPCHD_11 & 5.0 & 24 & $\mathrm{C}_{6.00} \mathrm{H}_{8.24} \mathrm{~S}_{0.13} \mathrm{Cl}_{0.05}$ & 5 & 2.6 \\
\hline
\end{tabular}


1. Formula normalized based on fact that number of carbon atoms remain the same after oxidation of PCHD in air and crosslinking with $\mathrm{S}_{2} \mathrm{Cl}_{2}$.

2. Calculations based on the increase of chlorine atoms per 6 carbon atoms.

\subsection{Sulfonation of XPCHD: Preparation of XPCHD_SPCHD fuel cell membranes}

The last two batches of XPCHD membranes in Table 1 (XPCHD_10 and XPCHD_11) were subjected to sulfonation. Various sulfonating reagents including acetyl sulfonate, chlorosulfonic acid $\left(\mathrm{ClSO}_{3} \mathrm{H}\right), \mathrm{ClSO}_{3} \mathrm{H} /$ dioxane, $\mathrm{ClSO}_{3} \mathrm{H} /$ diethyl ether, and $\mathrm{SO}_{3} /$ dioxane were used to achieve a broad range of membrane compositions. Several attempts were made to sulfonate the crosslinked membranes XPCHD with acetyl sulfonate and very low degrees of sulfonation (DS) (less than 5\%) were obtained. The reactivity of acetyl sulfonate appears to be insufficient for the sulfonation of the solid membrane [23]. Degrees of sulfonation (DS) lower than $25 \%$ can be obtained with $\mathrm{ClSO}_{3} \mathrm{H}$ complexes such as $\mathrm{ClSO}_{3} \mathrm{H}$ /dioxane, $\mathrm{ClSO}_{3} \mathrm{H} /$ diethyl ether. Therefore, $\mathrm{ClSO}_{3} \mathrm{H}$ complexes are not very efficient sulfonating reagents for XPCHD. On the other hand, $\mathrm{ClSO}_{3} \mathrm{H}$ is almost as efficient as the $\mathrm{SO}_{3} /$ dioxane complex. For example, with lower reaction temperature and shorter reaction time, the DS obtained in XPCHD_SPCHD_M1 was 20\%, which is almost as high as that in XPCHD_SPCHD_M2 sulfonated with $\mathrm{SO}_{3}$ /dioxane (see Table 2). As compared with $\mathrm{SO}_{3}$ /dioxane, $\mathrm{ClSO}_{3} \mathrm{H}$ is much easier to handle and readily available. Therefore, $\mathrm{ClSO}_{3} \mathrm{H}$ was used exclusively to prepare fuel cell membranes with DS higher than $40 \%$.

\section{Table 2}

Proton conductivities, degree of sulfonation (DS), ion exchange capacity (IEC) and sulfonating conditions of PCHD membranes.

\begin{tabular}{|c|c|c|c|c|c|c|c|}
\hline Samples $^{a}$ & $\begin{array}{l}\text { Conductivity } \\
(\mathrm{S} / \mathrm{cm})\end{array}$ & $\mathrm{DS}^{c}$ & $\begin{array}{c}\mathrm{IEC}^{d} \\
(\mathrm{meq} / \mathrm{g})\end{array}$ & \multicolumn{2}{|c|}{$\begin{array}{c}\text { Sulfonating Reagent } \\
\text { (\# of equivalent; concentration) }\end{array}$} & $\begin{array}{c}\text { Reaction } \\
\text { Temperature } \\
\left({ }^{\circ} \mathrm{C}\right)\end{array}$ & $\begin{array}{c}\text { Reaction } \\
\text { Time } \\
\text { (hours) }\end{array}$ \\
\hline XPCHD_SPCHD_L1 ${ }^{b}$ & 0.005 & $10 \%$ & 0.94 & \multicolumn{2}{|c|}{$\mathrm{ClSO}_{3} \mathrm{H} /$ dioxane $(5.50 ; 0.086 \mathrm{M})$} & 60 & 2 \\
\hline XPCHD_SPCHD_L2 & 0.006 & $22 \%$ & 2.04 & $\mathrm{CISO}_{3} \mathrm{H} / \mathrm{Et}_{2} \mathrm{O}$ & $(6.88 ; 0.107 \mathrm{M})$ & 60 & 4 \\
\hline XPCHD_SPCHD_L3 & 0.006 & $31 \%$ & 2.12 & $\mathrm{CISO}_{3} \mathrm{H}$ & $(2.75 ; 0.043 \mathrm{M})$ & 80 & 9 \\
\hline XPCHD_SPCHD_M1 & 0.032 & $20 \%$ & 1.68 & $\mathrm{ClSO}_{3} \mathrm{H}$ & $(4.81 ; 0.075 \mathrm{M})$ & 60 & 2 \\
\hline
\end{tabular}




\begin{tabular}{lllllllc} 
XPCHD_SPCHD_M2 & 0.043 & $24 \%$ & 1.98 & $\mathrm{SO}_{3} /$ dioxane & $(4.81 ; 0.075 \mathrm{M})$ & 80 & 4 \\
XPCHD_SPCHD_M3 $^{b}$ & 0.090 & $40 \%$ & 2.65 & $\mathrm{ClSO}_{3} \mathrm{H}$ & $(4.00 ; 0.071 \mathrm{M})$ & 80 & 1.5 \\
XPCHD_SPCHD_H1 & 0.112 & $67 \%$ & 3.64 & $\mathrm{ClSO}_{3} \mathrm{H}$ & $(6.88 ; 0.086 \mathrm{M})$ & 80 & 4 \\
XPCHD_SPCHD_H2 & 0.132 & $46 \%$ & 2.95 & $\mathrm{ClSO}_{3} \mathrm{H}$ & $(6.88 ; 0.086 \mathrm{M})$ & 60 & 4 \\
XPCHD_SPCHD_H3 & 0.135 & $45 \%$ & 2.78 & $\mathrm{ClSO}_{3} \mathrm{H}$ & $(5.50 ; 0.086 \mathrm{M})$ & 80 & 3 \\
\hline
\end{tabular}

${ }^{a}$ Membranes of the same size and thickness ( $0.5 \mathrm{~g}$ of PCHD and $100 \mathrm{~mm}$ in diameter) were used before sulfonation for all samples.

${ }^{b}$ The degree of crosslinking is $5 \%$, others are $3 \%$ unless otherwise stated.

${ }^{c}$ The degree of sulfonation is estimated by the increase of sulfur atoms per monomer unit based on elemental analysis.

${ }^{d}$ Calculated from data of elemental analysis.

Since sulfonation of solid membranes proceeds via a frontal mechanism [23], the sulfonating reagent such as $\mathrm{ClSO}_{3} \mathrm{H}$ must be able to diffuse into the interior of membrane in order to efficiently sulfonate the entire membrane rather than the surface only. High reaction temperatures $\left(60 \sim 80{ }^{\circ} \mathrm{C}\right)$ are necessary to swell our membranes and thus facilitate diffusion of the sulfonating reagent. Moreover, a large excess (4.0 7.0 molar equivalents) of sulfonating reagents must be used (see Table 2).

With chlorosulfonic acid and membranes XPCHD of the same size and thickness, three main parameters influence the sulfonation: the reaction time, the concentration of the sulfonating agent, and the reaction temperature. In general, higher DS is obtained with higher reaction temperature and/or longer reaction time. An increase in the concentration accelerated the reaction but also favored side reactions such as chain cleavage and/or crosslinking via sulfone formation. Another effect not quantified in this work was the decrease in mechanical strength with increasing concentration. Sulfonation in a $0.086 \mathrm{M}$ of $\mathrm{ClSO}_{3} \mathrm{H}$ solution at $80{ }^{\circ} \mathrm{C}$ resulted in a membrane (XPCHD_SPCHD_H1 in Table 2) that broke readily even in the wet state.

There is a general trend between degree of sulfonation (DS) and proton conductivity. Higher DS usually means higher proton conductivity. However, due to the complexity of chemical structures caused by different sulfonating conditions, higher DS does not always indicate higher proton conductivity for our membranes, which will be discussed in the next sections.

\subsection{Membrane proton conductivity}


Membranes with the broad range of chemical compositions described above were prepared and characterized for proton conductivity. Conductivity values measured at $100 \% \mathrm{RH}$ and room temperature are listed in Table 2. Inspection of this table shows that the membranes can be divided into three categories based on low $(\sigma<0.01 \mathrm{~S} / \mathrm{cm})$, medium $(0.01<\sigma<0.1 \mathrm{~S} / \mathrm{cm})$, and high conductivity $(\sigma>0.1$ $\mathrm{S} / \mathrm{cm}$ ). This broad range of values illustrates the sensitivity of conductivity to degree of sulfonation and chemical microstructure affected by different reaction conditions.

It is seen that membranes with higher DS usually have higher proton conductivity, as expected. However, sulfonation of alkene produces a complex mixture of compounds including the major products alkenesulfonic and hydroxyalkanesulfonic acids (see Scheme 1) [24, 25] as well as by-products such as sulfone crosslinks. These complex sulfonating products generate very different proton conductivities and greater chemical control is needed in future efforts of membrane optimization. For example, alkenesulfonic acids have much higher proton conductivity than hydroxyalkanesulfonic acids because of the delocalization effect of the double bonds in alkenesulfonic acids and tighter binding of hydronium ions due to the presence of hydroxyl groups in hydroxyalkanesulfonic acids, as suggested by our recent multi-scale simulation [26]. Also, sulfone crosslinks would not be thought of as proton hopping sites. With $\mathrm{ClSO}_{3} \mathrm{H} /$ diethyl ether as the sulfonating reagent and aqueous work-up, the major sulfonation product was 2-hydroxycyclohexanesulfonic acid rather than the cyclohexenesulfonic acid [27]. This is why sample XPCHD_SPCHD_L2 has proton conductivity much lower than that of XPCHD_SPCHD_M1 even though its DS is higher than that of XPCHD_SPCHD_M1. Sulfone crosslinks favored by sulfonating conditions used for XPCHD_SPCHD_L3 (longer reaction time) and XPCHD_SPCHD_H1 (higher concentration of $\mathrm{ClSO}_{3} \mathrm{H}$ and higher reaction temperature) are likely the reasons why these two membranes have lower proton conductivities, as seen in Table 2. Trends between DS and proton conductivity can be further complicated by other effects such as desulfonation, macromolecular fragmentation, loss of sulfur atoms from sulfur crosslinking bridges, and hydrogen bonding arrangements. For the latter, hydrogen bonding favored by 2-hydroxycyclohexanesulfonic acid could lead to morphologies conducive to better proton conduction. The effect of microstructures generated by various sulfonating condition has been studied by molecular dynamics simulation [26,28,29]. Good agreement between calculated conductivities and measured values [29] show that the relationship between membrane structure and relevant transport properties can be distilled, at least to a first order, to three key factors: acidity, confinement, and connectivity [30].

Although greater sulfonation does not always yield higher proton conductivity, it is absolutely necessary for DS to reach at least $40 \%$ to obtain high conductivity in our membranes, i.e., conductivity at room temperature and at $100 \% \mathrm{RH}$ is higher than $100 \mathrm{mS} / \mathrm{cm}$. Thus, $40 \% \mathrm{DS}$ is probably the 
minimum density of sulfonic acid groups that enable the resulting PEM to have sufficient connectivity of hydrophilic domains in order to obtain high proton conductivity.

Proton conductivity was further investigated using the Bekktech equipment as a function of RH at 30, 80, and $120{ }^{\circ} \mathrm{C}$; the results are shown in Fig. 2. The highest conductivity exhibited by XPCHD_SPCHD_H2 at $120{ }^{\circ} \mathrm{C}$ is $369.4 \mathrm{mS} / \mathrm{cm}$, which is considerably greater than that of Nafion ${ }^{\circledR}$ NRE-212 $(220.4 \mathrm{mS} / \mathrm{cm})$ under the same conditions. It is this $68 \%$ increase in conductivity at a temperature as high as $120^{\circ} \mathrm{C}$ that suggests that these PCHD-based membranes are promising materials that could be further optimized for use in high temperature fuel cells. These initial studies will be extended to optimize conductivity in the low RH region, i.e., reverse the vertical ordering of the curves therein.

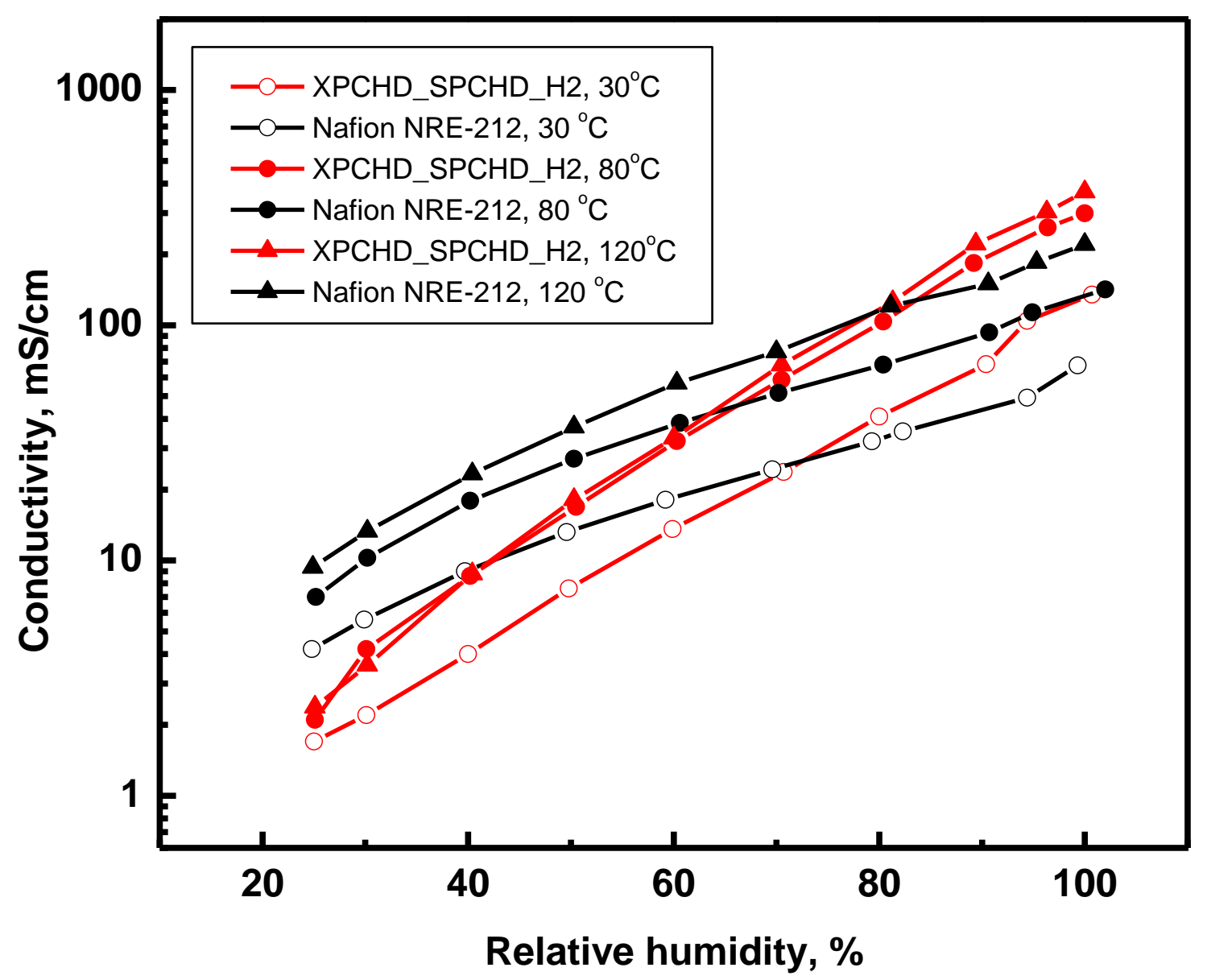

Fig. 2. Proton conductivity for membranes XPCHD_SPCHD_H2 and Nafion NRE-212, at $30{ }^{\circ} \mathrm{C}$, $80^{\circ} \mathrm{C}$, and $120^{\circ} \mathrm{C}$. 
Proton hopping between water molecules is mainly a thermally activated process so that conductivity increases with an increase in temperature. However, water evaporation from the membranes at temperatures over $100{ }^{\circ} \mathrm{C}$ causes conductivity to decline as some proton hopping pathways are destroyed. Proton conductivity vs. temperature behavior is due to the interplay of these two competing effects at high temperatures. Compared to Nafion ${ }^{\circledR}$, XPCHD_SPCHD_H2 shows a smaller increase in proton conductivity with temperature. This lower sensitivity of conductivity to temperature change above $80{ }^{\circ} \mathrm{C}$ implies lower conductivity activation energy for XPCHD_SPCHD_H2. As temperature increases from $80{ }^{\circ} \mathrm{C}$ to $100{ }^{\circ} \mathrm{C}$, Nafion ${ }^{\circledR}$ shows $116 \%$ and $24.3 \%$ increases in conductivity at $100 \%$ and $20 \%$ RH, respectively, while XPCHD_SPCHD_H2 shows only increase of $23.5 \%$ and $8.5 \%$, respectively. As compared with Nafion ${ }^{\circledR}$, this smaller increase in proton conductivity of XPCHD_SPCHD_H2 with temperature might be attributed to a higher $T_{\mathrm{g}}$ of PCHD, which makes the polymer backbone less mobile and less able to allow sulfonic acid groups to form continuous hydrophilic domains.

As expected, conductivity decreases as RH decreases. At $120{ }^{\circ} \mathrm{C}$, the conductivity decreases by more than two orders of magnitude for XPCHD_SPCHD_H2 but less than two orders of magnitude for Nafion ${ }^{\circledR}$ NRE-212, as RH decreases from 100 to $20 \%$. As compared with Nafion ${ }^{\circledR}$, the stronger conductivity dependence on RH of XPCHD_SPCHD_H2 is suggested to result from its semi-rigid polymer backbone $[17,18]$, which makes organization of sulfonic acid groups into contiguous structures to form continuous, hydrophilic, hydrogen-bonded proton conducting pathways more difficult. Due to its stronger conductivity dependence on hydration, XPCHD_SPCHD_H2 exhibits higher proton conductivity at $30{ }^{\circ} \mathrm{C}$ than Nafion NRE-212 in the range of $\mathrm{RH}$ of 100 to $70 \%$, the crossover point of the curves. When temperature rises from $30{ }^{\circ} \mathrm{C}$ to $80{ }^{\circ} \mathrm{C}$, the crossover point shifts to $65 \% \mathrm{RH}$ because proton conduction is thermally accelerated. However, faster evaporation of water at $120{ }^{\circ} \mathrm{C}$ shifts the crossover point to about $80 \% \mathrm{RH}$.

Proton conductivity behavior could be further understood by examining isothermal water uptake vs $\mathrm{RH}$ plots of the samples at $80{ }^{\circ} \mathrm{C}$ (see Fig. 3) which were generated by subjecting the hydrated samples to an isothermal desorption procedure using an accurate dynamic moisture sorption analyzer. 


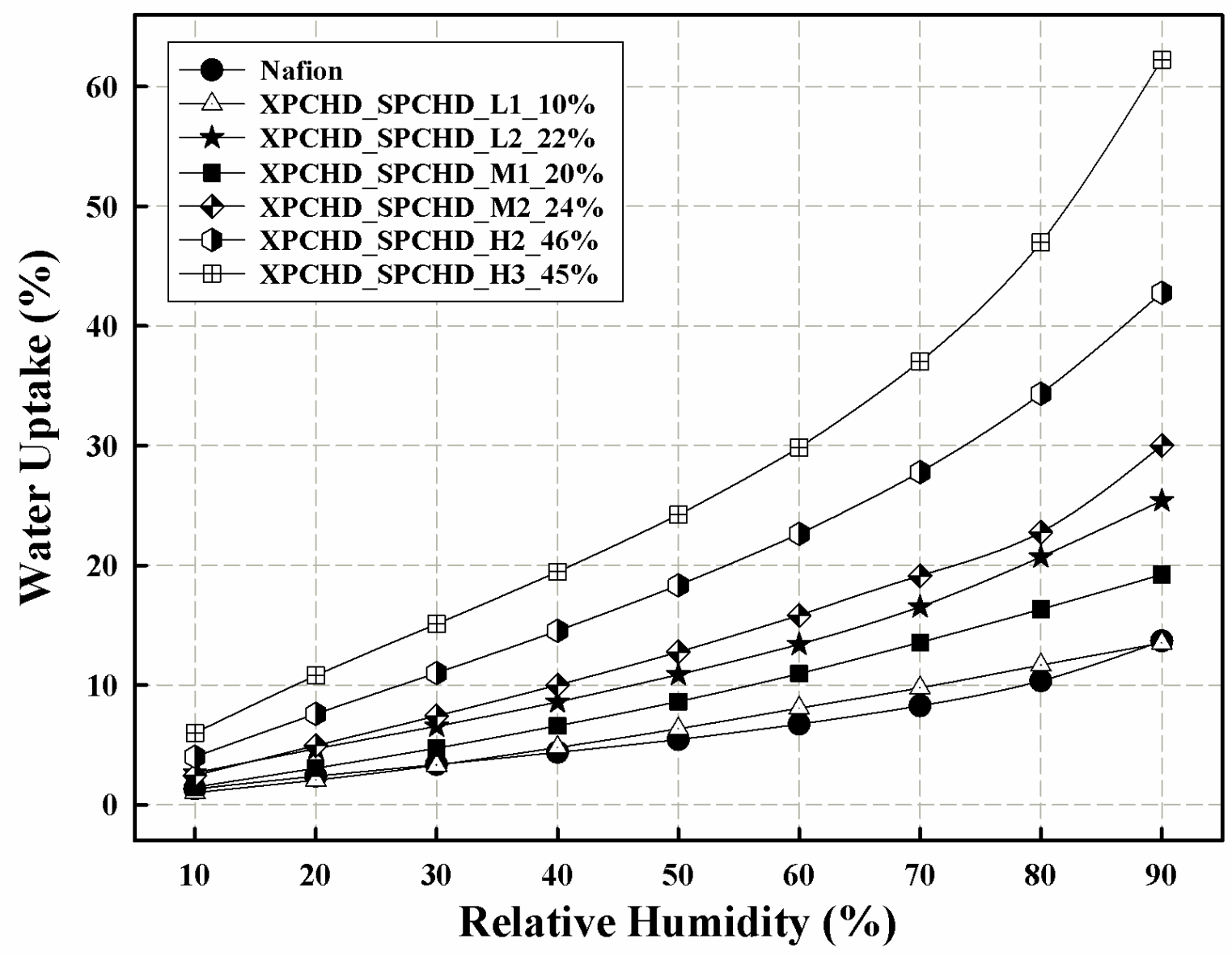

Fig. 3. Isothermal water uptake vs $\mathrm{RH}$ at $80{ }^{\circ} \mathrm{C}$ for samples prepared with reaction conditions listed in Table 2. Also plotted for comparison is data for a Nafion ${ }^{\circledR}$ benchmark membrane.

All of the curves lie above that of Nafion ${ }^{\circledR}$, which demonstrates greater hydration. The graphs in Fig. 3 show a monotonic trend of increased water uptake, at any given $\mathrm{RH}$, with increased degree of sulfonation. It seems that exceeding $40 \%$ DS caused a much greater increase in the water uptake as clearly seen for the XPCHD_SPCHD_H2 and XPCHD_SPCHD_H3 samples. Also, sample XPCHD_SPCHD_L2 exhibits slightly higher water uptake at all RH compared to the XPCHD_SPCHD_M1 sample although the latter showed more than twice an increase in conductivity under fully hydrated conditions, Table 2 . These phenomena could be linked to the minimum density of sulfonic acid groups required to have sufficient connectivity of hydrophilic domains in order to obtain high proton conductivity, as stated earlier [30]. Membrane XPCHD_SPCHD_H2 showed much higher water uptake than $\mathrm{Nafion}{ }^{\circledR}$ which reflects its ability to retain water even at high temperatures and accounts for its higher value of conductivity than that of Nafion ${ }^{\circledR}$ at $120{ }^{\circ} \mathrm{C}$ and $100 \%$ RH (369.4 vs $220.4 \mathrm{mS} / \mathrm{cm}$ ). Incorporated water not only promotes diffusion of hydrated protons but also proton hopping along hydrogen bonded pathways. 
PCHD-based membranes of high proton conductivity exhibit an interesting and vivid color change between the acid form and the sodium form (see Fig. 4). Immediately after sulfonation the membrane was completely black when immersed in water. After adding $\mathrm{NaOH}$, it was quickly hydrolyzed and turned translucent red within $5 \mathrm{~min}$. When the sodium form was put into $5 \mathrm{wt} \% \mathrm{HCl}$, the membrane turned black in less than 30 seconds. The acid form of the membrane can be converted back into its sodium form by immersing in $10 \mathrm{wt} \% \mathrm{NaOH}$ solution and the color change is completed in about $1 \mathrm{~min}$. Since the ion-exchange rate of $\mathrm{H}^{+}$is faster than that of $\mathrm{Na}^{+}$due to its smaller size, the sodium form changes into its acid form faster than the acid form changes into the sodium form. This color exchange occurs only for membranes of high proton conductivity, but not for those of low or medium conductivity.
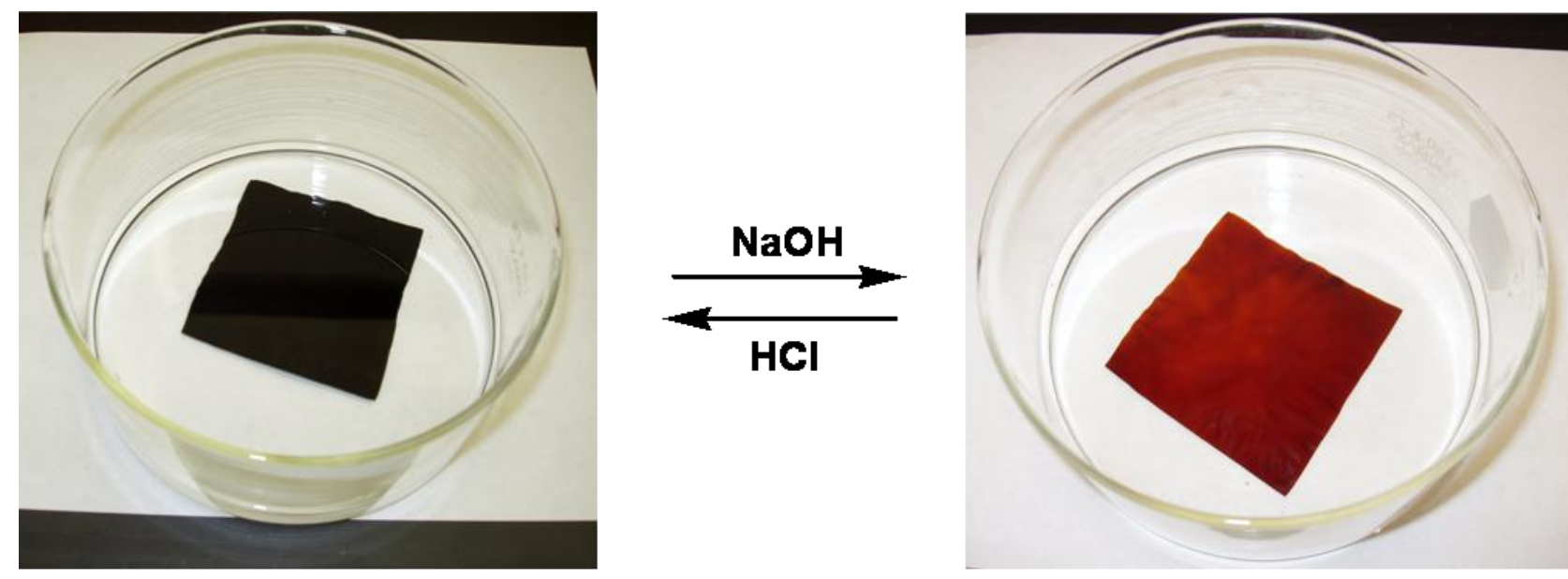

Fig. 4. Acid form (left) and sodium form (right) of XPCHD_SPCHD membranes in water.

\subsection{Thermogravimetric analysis (TGA)}

TGA studies were performed on these materials to determine their purely thermal degradative stability in $\mathrm{N}_{2}$ atmosphere, i.e. no thermo-oxidative effects. While the temperatures reached in these tests are above fuel cell operating temperatures, degradation temperatures reflect material cohesion that is related to membrane durability at lower temperatures.

Fig. 5 shows mass loss vs. temperature up to $800^{\circ} \mathrm{C}$ for membranes prepared under different reaction conditions. Degradation of these materials is seen to be a multi-step process which reflects chemical structural complexity that includes removal of $-\mathrm{SO}_{3} \mathrm{H}$ groups and crosslinks as well as chemical heterogeneity along the backbone itself. Major mass loss does not occur until up to $\sim 200^{\circ} \mathrm{C}$ for all membranes. Hence, these materials are stable with regard to pure thermal degradation and are rather cohesive with regard to molecular bonding. 


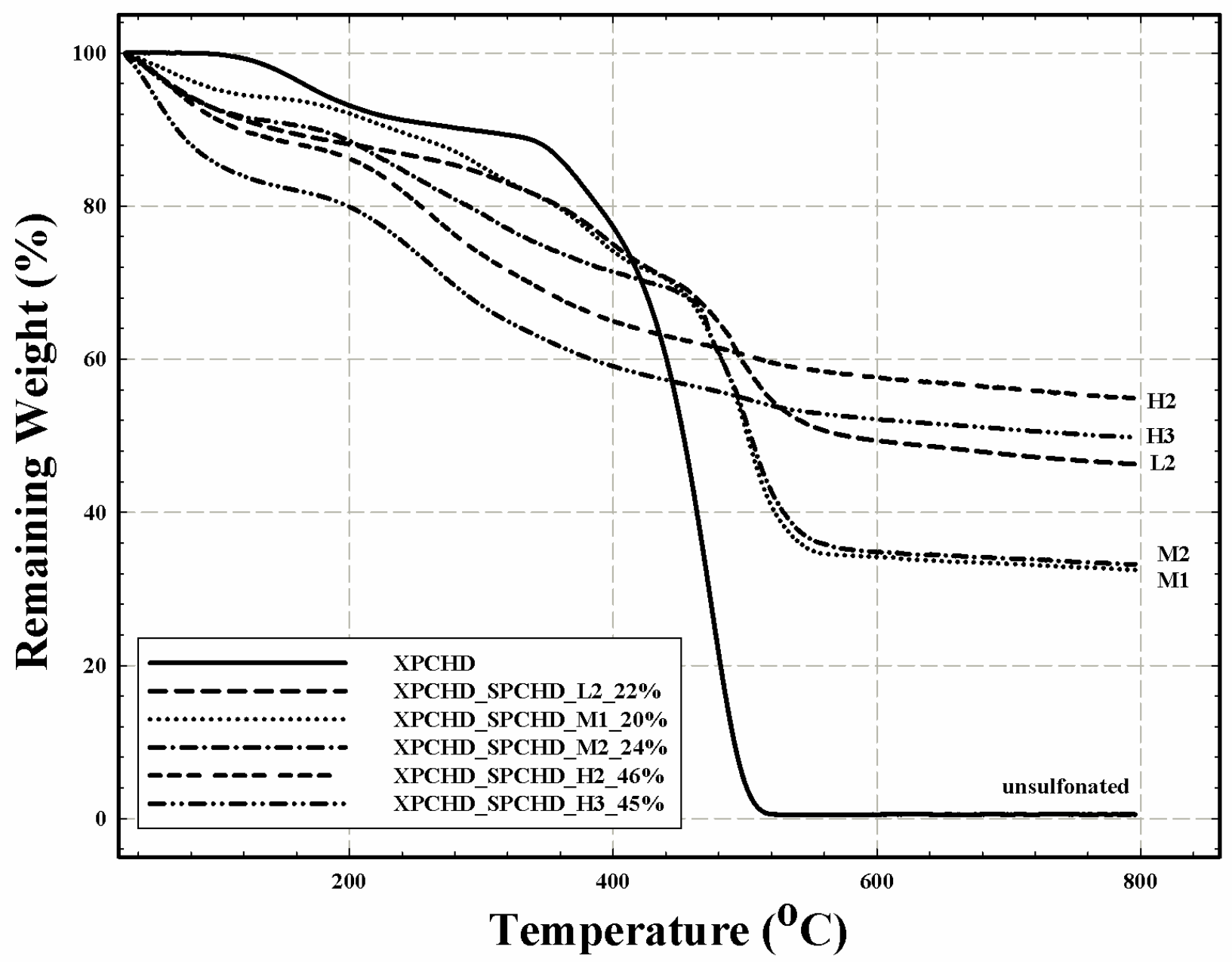

Fig. 5. TGA thermograms of samples prepared with reaction conditions listed in Table 2 .

Assignment of thermal mass loss events based on related reported work [16,31] is as follows: For all samples, except unsulfonated XPCHD, there is mass loss of $\sim 5$ to $20 \%$ at about $95{ }^{\circ} \mathrm{C}$. This initial loss is believed to be due to polymer chain depolymerization, which proceeds until more thermally stable units on the polymer backbone are reached [16]. The remaining backbone remains thermally stable until $200{ }^{\circ} \mathrm{C}$, after which more depolymerization takes place. Between 200 and $400{ }^{\circ} \mathrm{C}$ thermal stability is believed to depend on the strength of interactions among $-\mathrm{SO}_{3} \mathrm{H}$ groups and restrictive crosslinks. Then, the backbone shows more resistance to thermal degradation due to the formation of carbonized compounds formed from dehydrogenation of PCHD. These compounds can be regarded as graphitic as formed by carbonization of phenyl units. This would seem to be the reason why most samples show a remaining mass of 50 to $60 \%$ at the high temperature of $800^{\circ} \mathrm{C}$.

Fig. 5 shows strong correlation between proton conductivity and thermal stability. The conductivity values of the samples are in a narrower range, as seen in Table 2, and also exhibited similar thermal 
degradation behavior. The unsulfonated sample curve (solid line) has catastrophic failure at a lower temperature. This similarity in thermo-degradative behavior could reflect similar complexity in chemical structures for membranes with closer values of conductivities which would have similar degrees of $\mathrm{SO}_{3} \mathrm{H}$ group interactions. These results are diagnostic of good material cohesion that could express itself in terms of mechanical and chemical durability at lower fuel cell-relevant temperatures.

\section{Conclusions}

Linear poly(1,3-cyclohexadiene) was lightly crosslinked and then sulfonated to obtain novel high temperature fuel cell membranes that serve as versatile lower cost options to more robust materials having similar primary chemical structures. These membranes allow their structure and properties to be tuned by varying microstructure of the precursor PCHD, extent of crosslinking, and extent and type of sulfonation chemistry employed. Their crosslinked structure achieves morphologies that are not dependent on casting solvent or membrane casting conditions. Crosslinking is an essential process which enhances the integrity of fuel cell membranes. A broad range of membrane compositions were achieved by using different sulfonation conditions. Although the general trend between degree of sulfonation and proton conductivity is complicated by the complexity of sulfonation products, a minimum of $40 \%$ sulfonation seems to be required to achieve high proton conductivity in the sense of being comparable to, or higher than that of Nafion ${ }^{\circledR}$ benchmark membranes. Extent of crosslinking appears to be a less critical parameter in terms of conductivity but it strongly impacts swelling.

Membranes with various degrees of crosslinking and sulfonation were characterized for proton conductivity, thermal stability, and water capacity properties. All of the water vapor pressure vs. uptake curves lie above that of Nafion ${ }^{\circledR}$, which demonstrates greater hydration for these materials. Commensurate with this, the proton conductivities of some membranes were much higher than that of Nafion ${ }^{\circledR}$ membranes measured at the same experimental conditions of $100 \% \mathrm{RH}$ and $120{ }^{\circ} \mathrm{C}$.

Thermal (non-oxidative) stability of the PCHD membranes was characterized, using TGA, as related to material cohesion that is important for high temperature fuel cell operation. Thermal degradation of these materials is a multi-step process which reflects the complexity of these chemical structures that includes $\mathrm{SO}_{3} \mathrm{H}$ groups and crosslinks as well as chemical heterogeneity along the backbone itself. Membranes also showed, in some instances but not all, a correlation between conductivity and thermal stability. This similarity in thermodegradative behavior could reflect similar complexity in chemical structures for membranes with closer values of conductivities which would have similar degrees of $\mathrm{SO}_{3} \mathrm{H}$ group interactions. 
Brittleness of the sulfonated membranes has thus far prevented their thorough investigation by DMA. We are thus presently carrying out broadband dielectric spectroscopy experiments to study chains molecular motions in these membranes and correlate them with the water transport and proton conductivity. These data will be reported in a future publication.

\section{Acknowledgments}

The authors gratefully acknowledge the financial support of this research by the U. S. Department of Energy, EERE Program, under Grants \# DE-FG36-06GO16037 and DE-FG36-08GO88106. A portion of the work at the University of Tennessee was supported by the U. S. National Science Foundation (NSF EPS-1004083, TN Score Thrust 2). 


\section{References}

[1] Appleby AJ, Foulkes FR. Fuel cell handbook. New York: van Nostrand Reinhold; 1989.

[2] Chikashige Y, Chikyu Y, Miyatake K, Watanabe M. Macromolecules 2005;38:7121-7126.

[3] Binsu VV, Nagarale RK, Shahi VK. J Mater Chem 2005;15:4823-4831.

[4] Tezuka T, Tadanaga K, Hayashi A, Tatsumisago M. J Am Chem Soc 2006;128:16470-16471.

[5] Rhim JW, Park HB, Lee CS, Jun JH, Kim DS, Lee YM. J Membr Sci 2004;238:143-151.

[6] Steele BC, Heinzel A. Nature 2001;414:345-352.

[7] Rikukawa M, Sanui K. Prog Polym Sci 2000;25:1463-1502.

[8] Mauritz KA, Moore RB. Chem Rev 2004;104:4535-4585.

[9] Yang Y, Shi Z, Holdcroft S. Macromolecules 2004;37:1678-1681.

[10] Mathias MF, Makharia R, Gasteiger HA, Conley JJ, Fuller TJ, Gittleman CJ, Kocha SS, Miller DP, Mittelsteadt CK, Xie T, Yan SG, Yu PT. Electrochem Soc Interf 2005;25-35.

[11] Myers D, Niyogi S. Proceedings of Hydrogen Fuel Cells and Infrastructure Technologies Program Review. Crystal City, VA; 2006, http:/www.hydrogen.energy.gov/pdfs/review06/fc 1 myers.pdf.

[12] Roziere J, Jones DJ. Annu Rev Mater Res 2003;33:503-555.

[13] Yang Y, Holdcroft S. Fuel Cells 2005;5:171-186.

[14] Hong K, Mays JW. Macromolecules 2001;34:782-786.

[15] Natori I, Imaizumi K, Yamagishi H, Kazunori M. J Polym Sci, Part B: Polym Phys 1998; 36:16571668.

[16] Natori I, Natori S. Macromol Chem Phys 2006;207:1387-1393. 
[17] Yun SI, Terao K, Hong K, Melnichenko YB, Wignall GD, Britt PF, Nakamura Y, Mays JW. Macromolecules 2006;39:897-899.

[18] Mays JW, Kumar R, Sides SW, Goswami M, Sumpter BG, Hong K, Wu X, Russell TP, Gido SP, Avgeropoulos A, Tsoukatos T, Hadjichristidis N, Beyer FL. Polymer 2012;53:5155-5162.

[19] Mango LA, Lenz RW. Makromol Chem 1973;163:13-36.

[20] Zhong X, Francois B. Makromol Chem 1991;192:2277-2291.

[21] Huang T, Zhou H, Hong K, Simonson JM, Mays JW. Macromol Chem Phys 2008;209:308-314.

[22] Huang T, Messman JM, Mays JW. Macromolecules 2008;41:266-268.

[23] Walsby N, Paronen M, Juhanoja J, Sundholm F. J Appl Polym Sci 2001;81:1572-1580.

[24] Cremlyn RJ. Chlorosulfonic acid: a versatile reagent. Cambridge, UK: Royal Society of Chemistry; 2002.

[25] Gilbert EE. Chem Rev 1962;62:549-581.

[26] Wang Q, Keffer DJ, Deng S, Mays JW. Polymer 2013;54:2299-2307.

[27] Gilbert EE. Sulfonation and related reactions. New York: Interscience Publishers; 1965.

[28] Wang Q, Keffer DJ, Deng S, Mays JW. Polymers 2012;53:1517-1528.

[29] Wang Q, Suraweera NS, Keffer DJ, Deng S, Mays JW. Macromolecules 2012;45:6669-6685.

[30] Selvan ME, Keffer DJ, Calva-Munoz E. J Phys Chem B 2011;115:3052-3061.

[31] Williamson DT, Mather BD, Long TE. J Polym Sci: Polym Chem 2003;41:84-93. 